\title{
Empirical Research on the Priority Sequence of Entrepreneurial Factors of Agricultural Scientific Commissioners
}

\section{-Based on the Survey of 254 Agricultural Scientific Commissioners in Sichuan, China}

\author{
Lei $\mathrm{Xu}$ \\ College of Economic \& Management, Sichuan Agricultural University \\ 46 Xin Kang Street, Ya'an 625014, China \\ Tel: 86-151-8121-3216 E-mail: bailan8502@yahoo.cn \\ Xinhong Fu (Corresponding author) \\ Sichuan Agricultural University \\ Comprehensive Administration Building Room 327 \\ Sichuan Center for Rural Development Research, China \\ Tel: 86-139-8161-1038 E-mail: xinhongf@sina.com \\ Jun Li \\ College of Economic \& Management, Sichuan Agricultural University \\ 46Xin Kang Street, yaan 625014, China \\ Tel: 86-131-184-0167Ｅ-mail: lijun19851212@126.com
}

The research is financed by the sub-topics of the strategy study of strengthening agricultural foundation and ensuring national food security (08AJY034, the Major Program of the National Philosophical and Social Science Foundation of China) " the macro-control system study of strengthening agricultural foundation and ensuring national food security (2008-2011) " and the research project of Science and Technology Agency in Sichuan Province "the long-term mechanism of effective operations of agricultural scientific commissioners (2009-2010) "and the support plan of science and technology of Science and Technology Agency in Sichuan Province "the operation mechanism and the demonstration of pattern innovation of agricultural scientific commissioners' entrepreneur".

\begin{abstract}
Based on the survey of 254 agricultural scientific commissioners in Sichuan, China, this paper selects eight factors affecting agricultural scientific commissioners' entrepreneurs. And agricultural scientific commissioners include two types, which are those who have been entrepreneurial and those who are ready to act as entrepreneurs. The work aims to determine if there exists significant demand differences for factors affecting the two types of commissioners with the method of Wilcoxon rank sum test, and then to rank the factors-priority sequence. The result shows that, at present, the most urgently demanded elements of agricultural scientific commissioner's entrepreneurs are the three platforms for information service, for financial service, and for research-outcomes shown and exchanged, while the demand for the policies is relatively weak.
\end{abstract}

Keywords: Agricultural scientific commissioners, Entrepreneurs, Factors, The priority sequence

\section{Introduction}

Agricultural scientific commissioners (referred to as "commissioners" below) first appeared in Nanping City, Fujian Province of China. And the system of commissioners is defined as follows: with the special security policies and incentive policies, the government adds special resources, and selects the scientific personnel, who are good at technology and management, to stay at the grassroots to promote scientific technologies and 
implement technology items. With the system from the "Nanping Experience" to "Ningxia model", the commissioners have achieved a great deal, and their entrepreneurial enthusiasm is also very high. Commissioners' entrepreneur is such an activity in which the commissioners root the new production factors, such as the technology, the capital, management, information and etc. in rural areas. As a breakthrough, this activity has promoted economic and social development for the new era of China's rural areas, especially the western rural areas of less developed market economy (Yue Zhen, Lai Maosheng, 2007, pp.114-117).

From the literature, it can be found that the researches of commissioners have been focused on the following aspects: one is about the basic issues of commissioners-system, such as the characteristics and functions of commissioners-system (Ding Zili, Jiao Chunhai etc., 2009, pp.305-306), the innovative models, the mechanisms and effects (Chai JianFeng, 2007, pp.128-132; Tan Xuewen, 2007, pp.60-68), the construction of performance evaluation index (Zhu Min, Li ShouShan etc., 2009, pp.19-23) and etc.; the other is about the operations of the commissioners-system. Here, the research about commissioners ' entrepreneur is mainly focused on the status and problems of commissioners 'entrepreneur, entrepreneurship mechanism and how to promote the entrepreneurial enthusiasm. Zhang Fang, Zhang Shiliang (2007, pp.33-35) considered that commissioners' entrepreneur stemmed from the demands of the masses, the exploration of the grassroots and the innovation of the practice. It is an inevitable byproduct of the combination of technology and economy and the combination of technological personnel and farmers during the in-depth reform of modern agriculture in China. Commissioners' entrepreneur is a systemic engineering and an important starting point to balance the urban and rural development (Zhang Laiwu, 2008, pp.14-18; Cheng Ziliang, 2009, pp.32-33). Wu Jinming, Zhang Sha etc. (2008, pp.33-35) made a research on the mechanism of commissioners' entrepreneur, and put forward the model options about technical service and the entrepreneurial institutional arrangements based on the special legal regime. Zhang Yu (2009, pp.49-51) made a discussion on the commissioners' entrepreneurial activity in the investment and financing mechanism and proposed that the rural credit cooperatives should open up a range of new varieties of financial services for the agricultural development, and this could support commissioners' entrepreneurial activity more effectively. Wang Zhengyi (2009, pp. 66-67) deemed that commissioners' entrepreneur should be based on Chinese agricultural situation, and need departmental interaction and ideological emancipation. Zeng Yesong (2009, pp.38-41) thought that in order to guide the commissioners to entrepreneur in the grassroots, the mechanism's advantageous features, such as the government promotion, market-driven, interest-driven, personal values motivate, must be institutionalized, an easily policy environment, work environment, service environment and public-opinion environment must be created, the urban-rural division, regional boundaries, industry boundaries, departmental boundaries should be broken, service areas for commissioners should be expanded, and commissioners-service models and management-system should be consummated.

It can be seen from the above literature that current researches about commissioners' entrepreneur mainly focus on the theoretical stage or on the summary of commissioners' entrepreneurial activity. However the researches of factors affecting commissioners' entrepreneur in the empirical view are few. The commissioners' entrepreneurial activity is one of the effective means to speed up the development of the rural economy; it must of great significance of the theoretical and practical way to make a study on the factors affecting commissioners' entrepreneur.

\section{Selection of the factors affecting commissioners' entrepreneur}

At present, there are many areas to be improved urgently for entrepreneurial environment in China, especially policy and cultural environments.(Yang Zhaoli, 2007,pp.9-10).The ideal entrepreneurial environment should be good platforms (Ye Yiguang, Liu Zhizhong, 2004, pp.228-232), and it also needs government supported policies. Entrepreneurial platforms can provide necessary infrastructure and a range of support services, which are demanded for commissioners ' entrepreneur, such as the places for research, facilities for communication, and etc. And the platforms can assist the commissioners in resolving sources of funding, give support in technology, marketing, consulting, training, management, policy, legal and etc., create necessary conditions for enterprises-nurture and growth, reduce entrepreneurial risk and costs, and make the research-outcomes into commodities rapidly, so as to make the enterprises founded by the commissioners having a foothold in the market-competition (Han Xinchuan, Wang Boliang, 2006, pp.123-125).

Commissioners' entrepreneurial activity is generated during the running of the commissioners-system, with characteristics different from others. Based on the survey of 254 commissioners in Sichuan Province, it can be found that more than half of commissioners are from the institution position and do it for part-time job. While engaged in commissioners' work, they also have to complete the original work. It shows that commissioners run a greater workload than other entrepreneurs. Therefore, commissioners' entrepreneurial activity needs a wide range of supports. So it is very necessary to gain the support from the entrepreneurial platforms and the 
government-related policies.

In this paper, five entrepreneurial platforms are selected: the information service platform, technology incubated platform, financial service platform, technology patents and property transactions platform, research-outcomes shown and exchanged platform; three policy factors are selected: the land preferential policy, tax relief policy and commissioners-operating mechanism. Among these factors, the information service platform can provide the information from the market, talents, and management for commissioners; the technology incubated platform can improve the successful rate of technical research; the financial service platform will broaden the capital channels for commissioners' entrepreneur; the technology patents and property transactions platform can improve commissioners-enthusiasm engaged in technical research; the research-outcomes shown and exchanged platform can contribute researches mercerization. Three policy factors can provide policy-support for commissioners' entrepreneur.

This article, based on the survey of 254 commissioners in Sichuan province, makes an analysis of the eight factors which affect commissioners' entrepreneur. Suppose that the commissioners-demand for each factor is different, and the government and the community should pay great attention on the factors that commissioners need most urgently.

\section{Data sources and sample characteristics}

\subsection{Data sources}

The paper' data is from the survey of 254 commissioners in Sichuan province, and the study is for those commissioners who have been entrepreneurial and those who are ready to act as entrepreneurs. The areas surveyed are Chengdu City, Luzhou City, Suining City and Meishan City, where commissioners-work is more representative than in other cities. There are 280 questionnaires issued, of 254 copies valid, and the effective rate is $90.7 \%$. There are 44 copies for those who have been entrepreneurial, 123 copies for those who are ready to act as entrepreneur and 87copies for those who are unwilling to act as entrepreneur.

\subsection{The descriptive analysis of the sample's entrepreneurial situation}

There are $61.4 \%$ of those commissioners, who have been entrepreneurial, choosing the part-time entrepreneurship; for the entrepreneurial types, the selection for individual entrepreneur and partners (in entrepreneurial teams) is on each 50\%; for the entrepreneurial organization forms, $63.6 \%$ of commissioners take the form of specialized cooperative economic organizations. The commissioners, who are ready to act as entrepreneur, have almost the same choice as the commissioners who have already been entrepreneurial.

\section{Analysis methods and the process}

\subsection{The introduction of rank sum test method}

The rank sum test is an important type of non-parameter statistical methods, which can be used to test whether the one-way order of any two independent samples are from the same general or the overall distribution of two independent samples are the same or not. While the Wilcoxon rank sum test is one kind of non-parameter rank test methods. As for the one-way 2 -C contingency table, Wilcoxon rank sum test can be used to test the hypothesis: whether the location of two independent samples is the same in distribution or not. In this article, Wilcoxon rank sum test is to be used to test the hypothesis: for the commissioners of two entrepreneurial statuses -those who have been entrepreneurial and those who are ready to act as entrepreneur, there is no significant difference in demand for certain factor.

\subsection{The priority sequence of the factors affecting commissioners-entrepreneur}

\subsubsection{Analysis about the demand difference for the factors}

In this paper, the demands for the factors are classified into five levels: the most needed, more needed, general needed, not really needed and not needed. Considering that there may exist different demands for the factors affecting the commissioners' entrepreneur, so firstly the Wilcoxon rank sum test is used to test it. The results can be obtained by running the SPSS17.0 software. And the results of Mann-Whitney test and the statistic test are in Table 1, Table 2 .

From Table 1 and Table 2, it can be seen that the approximate probability of each factor is greater than 0.05 , which is the significant lever. And it indicates that there is no significant demand difference between the factors. Take the information service platform for example. Mann-Whitney U value is 2636.000, Wilcoxon W value is 3626.000 , and the approximate probability value (both sides) is $0.752>0.05$. So the original assumption is proved, that is to say, there is no significant demand difference for the information service platform. 


\subsubsection{The priority sequence of the factors affecting commissioners' entrepreneur}

It can be drawn through the above analysis that the demands for the factors are consistent for the commissioners in the two statuses. Therefore, take the commissioners in those two statuses as a whole, and prioritize the factors affecting commissioners' entrepreneur. Assign in accordance with the demand extent for 1, 2, 3, 4, 5, multiplicity the assignment and the frequency, and then add them. The lowest score shows that factor is the one that the commissioners need most. The priority sequence of the factors is in Table 3. The analysis of the table is as follows:

(1) The demand for the information service platform is the greatest. During the investigation, the commissioners reflected that the greatest difficulty encountered by entrepreneur is lack of the market-information. That causes the commissioners not to sell products at a right price and the profits cannot be guaranteed. Therefore, the creation and perfection for the information service platform is urgently needed for commissioners.

(2) The financial service platform ranks in the second place. As can be seen from the survey, the initial source of funds of those commissioners who have been entrepreneurial is a free deposit. With companies-scales expanding, the commissioners need millions of money to maintain the normal operations under enormous financial pressure. At this moment, to solve this money problem can greatly improve commissioners' entrepreneurial enthusiasm. The financial services platform can broaden the capital channels. Therefore, the financial services platform is extremely important to improve commissioners' entrepreneurial enthusiasm.

(3) That the research-outcomes shown and exchanged platform in the third place indicates that the commissioners have already realized the importance of research-outcomes shown and exchanged. The research-outcomes, which are created by the commissioners, need to be mercerization. Therefore, the communication platform is necessary to facilitate the research-outcomes transformation smoothly.

(4) The R\&D activity needs a wide range of resources, such as the manpower, material and financial resources and etc. At present it is difficult to provide the whole above resources for a single enterprise. However, the technology incubated platform can satisfy the conditions and can improve the successful rate of technical research. That the technology patents and property transactions platform in the end shows that commissioners-demand for the platform is not very strong compared to other platforms. Perhaps with the expansion of enterprise scale, commissioners will gradually realize the importance of it.

(5) Among the three policy factors, the operating mechanism of commissioners is located in the top. That indicates the current operating mechanism is not very conducive to commissioners' entrepreneur. The land preferential policy and tax relief policy at the back show that the two systems may be of little effect on commissioners' entrepreneur compared to other factors.

\section{Conclusions and Advices}

\subsection{Conclusions}

Conclusions can be drawn from the above analysis: (1) there is no significant demand difference between the entrepreneurial factors for the commissioners, who are in those two statuses; (2) of the factors affecting commissioners' entrepreneur, the platforms for information, financial service and research-outcomes shown and exchanged are mostly needed, and the demands for the land preferential policy and tax relief policy are relatively weak. The two conclusions show that solving the problems of the information, funds and research-outcomes communication can greatly improve commissioners' entrepreneurial enthusiasm.

\subsection{Advices}

(1) Speed up the construction of the necessary platforms, especially the platforms for information, financial service and research-outcomes shown and exchanged. During the construction, the government should establish a good market-environment in order to ensure the development of the entrepreneurial platforms smoothly.

(2) The government should formulate policies which are conducive to entrepreneurship, and revise the adverse policy to promote commissioners' entrepreneurial enthusiasm.

(3) Except for the most needed factors, other factors should not be ignored.

\section{References}

Chai Jianfeng. (2007). The analysis on the popularizing system of special commissioners in science and technology under the new countryside construction. In Science and Management of S. \& T., 1, 128-132.

Cheng Ziliang. (2009). Commissioners' entrepreneurial activity is an important starting point to balance urban and rural development. China Rural Science \& Technology, 2, 32-33. 
Ding Zili, Jiao Chunhai, GuoYing and WangYanming. (2009). The characteristic and function of scientific special commissioner system. Chinese Agricultural Science Bulletin, 9, 305-306.

Han Xinchuan and Wang Boliang. (2007). The comparative study on the entrepreneurial platform in china. Scientific Information Development \& Economy, 5, 123-125.

Tan Xuewen. (2007). The mechanism and effects of commissioner system in Ningxia. Chinese Rural Economy, 4 , 60-68.

Wang Jinming,Zhang Sha and Wang Kuiwu. (2008). The research of commissioners' entrepreneurial mechanism based on "three-dimensional control" and a special legal system. China Rural Science \& Technology, 12, 33-35.

Wang Zhengyi. (2009). Think about the further development of the commissioners' entrepreneur. China Rural Science \& Technology, 2, 66-67.

Yang Zhaoli. (2007). Discussion about incentives and policy recommendations for Chinese entrepreneurial activity. Group Economic Research, 248, 9-10.

YeYiguang and LiuZhiZhong. (2004). Discussion about the Connotation of creation environment and the index system of function. Social Sciences In Nanjing, s2, 228-232.

Yu Chuanhua. (2007). SPSS and Statistical Analysis. Beijing: publishing house of Electronics Industry, (chapter7).

YueZhen and Lai Maosheng. (2007). The innovative of commissioners-system. Forum on Science and Technology, 3, 114-117.

Zeng Yesong,Zhao Jianjun. (2009). A radical system innovation. China Rural Science \&Technology, 6, 62-63.

Zeng Yesong. (2009). The guide needed in the process of commissioners' entrepreneurial activity. China Rural Science \& Technology, 2, 38-41.

Zhang Fang, Zhang Shiliang. (2007). Develop the commissioners' entrepreneurial activity in Chinese modern agriculture. China Rural Science \& Technology, 10, 33-35.

Zhang Laiwu. (2008). Commissioners' entrepreneur is a systemic engineering to balance urban and rural development. China Rural Science \& Technology, 11, 14-18.

Zhang Yu. (2009). The theoretical exploration of investment and finance mechanism about commissioners' entrepreneurial activity. China Rural Science \& Technology, 3, 49-51.

Zhu Min, LiShouShan and ChenTong. (2009). Construction of the evaluation of the technical envoy systems performance and its empirical analysis. Journal of Pingxiang College, 1, 19-23.

Table 1. Mann-Whitney test results

\begin{tabular}{|c|c|c|c|c|}
\hline \multirow{3}{*}{ Factors } & \multicolumn{4}{|c|}{ Entrepreneurial statuses* } \\
\hline & \multicolumn{2}{|c|}{ Have been Entrepreneurial } & \multicolumn{2}{|c|}{ Be ready to act as entrepreneurs } \\
\hline & Mean rank & Mean sum & Mean rank & Mean sum \\
\hline The information service platform & 82.410 & 3626.000 & 84.570 & 10402.000 \\
\hline The technology incubated platform & 77.910 & 3428.000 & 86.180 & 10600.000 \\
\hline The financial service platform & 82.250 & 3619.000 & 84.630 & 10409.000 \\
\hline $\begin{array}{l}\text { The technology patents and } \\
\text { property transactions platform }\end{array}$ & 83.410 & 3670.000 & 84.210 & 10358.000 \\
\hline $\begin{array}{l}\text { The research-outcomes shown and } \\
\text { exchanged platform }\end{array}$ & 77.150 & 3394.500 & 86.450 & 10633.500 \\
\hline The land preferential policy & 88.860 & 3910.000 & 82.260 & 10118.000 \\
\hline The tax relief policy & 91.660 & 4033.000 & 81.260 & 9995.000 \\
\hline $\begin{array}{l}\text { The commissioners-operating } \\
\text { mechanism }\end{array}$ & 85.050 & 3742.000 & 83.630 & 10286.000 \\
\hline
\end{tabular}


Table 2. Test statistic results

\begin{tabular}{l|ccc}
\hline \multicolumn{1}{|c|}{ Test statistic } & Mann-Whitney U & Wilcoxon $\mathrm{W}$ & $\begin{array}{c}\text { Approximate } \\
\text { probability } \\
\text { factors }\end{array}$ \\
\hline $\begin{array}{l}\text { The information service platform } \\
\text { The technology incubated platform }\end{array}$ & 2636.000 & 3626.000 & 0.752 \\
The financial services platform & 2438.000 & 3428.000 & 0.300 \\
The technology patents and property & 2629.000 & 3619.000 & 0.744 \\
transactions platform & 240.000 & 3670.000 & 0.921 \\
The research-outcomes shown and & & & \\
exchanged platform & 2404.500 & 3394.500 & 0.239 \\
The land preferential policy & & & \\
The tax relief policy & 2369.000 & 10118.000 & 0.418 \\
The commissioners-operating & 2666.000 & 10286.000 & 0.203 \\
mechanism & & & 0.856 \\
\hline
\end{tabular}

*Grouping variables are the entrepreneurial statuses.

Table 3. The priority sequence of the factors affecting commissioners' entrepreneur

\begin{tabular}{cllcc}
\hline \multicolumn{1}{c}{ Factors } & Scores & Ranking \\
\hline \multirow{5}{*}{ Platforms } & \multicolumn{1}{c}{ The information service platform } & 228 & 1 \\
\cline { 2 - 4 } & The technology incubated platform & 319 & 4 \\
\cline { 2 - 4 } & The financial service platform & 248 & 2 \\
\cline { 2 - 4 } & The technology patents and property transactions platform & 347 & 6 \\
\cline { 2 - 4 } & The research-outcomes shown and exchanged platform & 311 & 3 \\
\hline \multirow{5}{*}{ Policies } & The land preferential policy & 375 & 8 \\
\cline { 2 - 4 } & The tax relief policy & 394 & 5 \\
\cline { 2 - 4 } & The commissioners-operating mechanism & 340 & 7 \\
\hline
\end{tabular}

